\title{
Período de Descanso, Valor Nutritivo e Desempenho Animal em Pastagem de Panicum maximum cv. Mombaça sob Lotação Intermitente ${ }^{1}$
}

\author{
Magno José Duarte Cândido², Emerson Alexandrino ${ }^{3}$, Carlos Augusto de Miranda Gomide ${ }^{4}$, José \\ Alberto Gomide ${ }^{5}$, Walter Esfrain Pereira ${ }^{6}$
}

RESUMO - Avaliaram-se, ao longo dos períodos de pastejo, o valor nutritivo de amostras de forragem, colhidas à mão, e o desempenho animal em pastagem de capim-mombaça sob lotação intermitente, com três períodos de descanso (PD). Os PDs (tratamentos) foram definidos em função do tempo necessário para a expansão de 2,5; 3,5 e 4,5 novas folhas por perfilho. A área experimental foi dividida em cinco ou seis piquetes por tratamento. Utilizaram-se cinco novilhos mestiços (Holandês x Zebu) por tratamento, como animais de prova, além de outros, de equilíbrio, para se garantir índice de área foliar (IAF) residual de 2,0, ao final do $6^{0}$ dia de pastejo. Os piquetes receberam adubação em cobertura de $\mathrm{N}, \mathrm{P}_{2} \mathrm{O}_{5}$ e $\mathrm{K}_{2} \mathrm{O}$, nas doses de 100 ; 25 e $100 \mathrm{~kg} / \mathrm{ha}$, respectivamente, divididas em duas aplicações, no início e meados do período experimental. As avaliações consistiram da determinação da digestibilidade in vitro da matéria seca (DIVMS) e da composição bromatológica de amostras da forragem, colhidas manualmente simulando o pastejo dos animais, e das estimativas do consumo de forragem e do peso dos animais de prova. O prolongamento do período de descanso de 2,5 para 4,5 novas folhas por perfilho pouco afetou o valor nutritivo da forragem, que foi mais comprometido pelo período de pastejo. Entretanto, grandes diferenças foram observadas no desempenho e no rendimento animal, em resposta aos períodos de descanso. O mais longo PD comprometeu o desempenho animal (433 g/novilho $\times$ dia) e o rendimento de peso (363 kg/ha), ao passo que o menor PD favoreceu o desempenho (704 g/novilho $\times$ dia) e o rendimento animal (546 kg PV/ha). Concluiu-se que o PD do capim-mombaça não deve exceder o tempo necessário para a expansão de 2,5 novas folhas por perfilho, que variou de 24 a 41 dias, ao longo do período experimental.

Palavras-chave: composição química, consumo de forragem, digestibilidade, excreção fecal, ganho de peso vivo

\section{Rest Period, Forage Nutritive Value and Steer Performance on Panicum maximum cv. Mombaça Pasture under Intermittent Stocking}

\begin{abstract}
It was assessed the nutritive value of hand plucked forage samples collected along the grazing period and the animal performance on Mombaçagrass pasture under intermittent stocking with three rest periods (RP). The RPs were defined by the time required for the expansion of 2.5, 3.5, and 4.5 new leaves per tiller, after six days grazing period. The experimental area was divided into five paddocks for the 2.5 new leaves RP and six paddocks for the 3.5 and 4.5 new leaves RPs. Five crossbreed (Holstein x Zebu) steers were randomly assigned to each treatment (RP) as tester animals; put and taken steers were used to assure residual leaf area index of about 2.0, by the end of each grazing period. A NPK fertilization of 100 ; 25 and $100 \mathrm{~kg} /$ ha of $\mathrm{N}, \mathrm{P}_{2} \mathrm{O}_{5}$ and $\mathrm{K}_{2} \mathrm{O}$, respectively, divided into two applications, was broadcasted on each paddock at the beginning and middle of the experimental period. The following evaluations were performed: chemical composition and in vitro dry matter digestibility of hand plucked forage samples, forage intake and live weight gain of tester animals. The rest period had less effect on forage nutritive value than the grazing period; still, the rest period affected steer live weight gains. The longest RP resulted in low animal performance (433 g/steer $\times$ day) and yield (363 kg BW/ha); on the other hand, the shortest RP favored high animal performance (704 g/steer $\times$ day) and yield (546 kg BW/ha). It is concluded that rest period of Panicum maximum cv. Mombaça should not exceed the time for the expansion of 2.5 new leaves per tiller, which varied from 24 to 41 days over the experimental period.
\end{abstract}

Key Words: chemical composition, chromium sesquioxide, forage digestibility, fecal output, forage intake, live weight gain

\footnotetext{
${ }_{1}^{1}$ Parte da tese de Doutorado do primeiro autor; pesquisa financiada pela FAPEMIG.

${ }^{2}$ Professor Adjunto, Departamento de Zootecnia, Universidade Federal do Ceará, Av. Mister Hull, 2977, Campus Universitário do Picí, Fortaleza-CE, 60970-355, TEL: (85)4008-9711, FAX: (85)4008-9701 (mjdcandido@gmail.com).

${ }^{3}$ Professor Adjunto de Nutrição e Pastagem do Departamento de Agronomia, Universidade Federal de Rondônia, Campus de Rolim de Moura Avenida Norte Sul, 7300, Bairro Nova Morada, Rolim de Moura, Rondônia, CEP: 78987-000.

4 Pesquisador da Embrapa/CNPGL (cagomide@cpatc.embrapa.br).

${ }^{5}$ Professor Aposentado, UFV - Viçosa-MG (jagomide@ufv.br).

6 Professor Universidade Federal da Paraiba.
} 


\section{Introdução}

O potencial forrageiro de uma espécie vegetal pode ser avaliado em função do rendimento de matéria seca e da digestibilidade dos seus constituintes (Reid et al., 1959). Embora por muito tempo tenha-se enfatizado a avaliação da composição bromatológica e da digestibilidade da forragem, são crescentes as evidências de que, sob condições de pastejo, outras características devem ser também consideradas na determinação do potencial de rendimento forrageiro.

De fato, o arranjo estrutural dos componentes do dossel é um importante componente do rendimento animal sob pastejo e sofre grande influência das estratégias de manejo adotadas (Silva et al., 1994a).

Em estudo que avaliou o rendimento de Poa pratensis sob três alturas de pastejo (11,5; 13,5 e $15,5 \mathrm{~cm}$ ) e duas intensidades de utilização (50 e 60\%), Bryan et al. (2000) verificaram que a altura do dossel apresentou relação direta com a massa de forragem pré-pastejo, que variou entre 1855, 2130 e 2350 kg/ha. Não se observou grande diferença entre os dosséis quanto ao valor nutritivo. A forragem dos dosséis pastejados em altura mais baixa apresentou teores ligeiramente inferiores de fibra em detergente ácido e níveis superiores de proteína bruta.

Duble et al. (1971) relataram ganho médio diário superior a 1,1 kg por animal, em pastagens com massa seca de forragem acima de $500 \mathrm{~kg} / \mathrm{ha}$, com digestibilidade média da matéria seca da forragem igual ou acima de $66 \%$.

Motazedian \& Sharrow (1990) constataram relação inversa entre rendimento de massa seca digestível e freqüência de desfolhação em dossel misto de Lolium perenne e Trifolium subterraneum. Em três anos, o rendimento médio de massa seca digestível aumentou de 3.000 e $4.250 \mathrm{~kg} / \mathrm{ha}$, sob freqüência de desfolha de sete dias, para valores acima de $5.500 \mathrm{~kg} / \mathrm{ha}$, quando desfolhado a cada 49 dias. Entretanto, a digestibilidade da matéria seca decresceu.

Apesar do maior rendimento de massa seca de forragem sob regime de desfolha de longo período de descanso, a qualidade e as características estruturais do dossel são freqüentemente comprometidas. Santos et al. (1999) verificaram redução na relação folha/ colmo de Panicum maximum cv. Mombaça de 1,32 para 0,99, quando a freqüência de desfolhação reduziu-se de 28 para 48 dias. Gomide \& Gomide (2001) também observaram redução de 2,8 para 1,7 na relação folha/colmo do dossel do mesmo cultivar submetida, respectivamente, a períodos de descanso de 2,5 e 4,5 novas folhas expandidas por perfilho.

Stobbs (1973a) ressaltou que não só a massa de forragem, como também a proporção de folhas, determinam o rendimento animal, sobretudo em pastagens de gramíneas $\mathrm{C}_{4}$, que apresentam forte estreitamento da relação folha/ haste com o avançar da idade. Isso porque as características estruturais do dossel têm grande influência sobre o comportamento ingestivo e o consumo de forragem (Moore \& Sollenberger, 1997).

O consumo de forragem pelos animais em pastejo é determinado pelo tempo de pastejo e pela taxa de ingestão (Allden \& Whittaker, 1970), que varia em função do tamanho do bocado e da taxa de bocado, duas variáveis fortemente afetadas pela estrutura do dossel (Cosgrove,1997)

A elevação da altura do dossel compromete o consumo, em virtude da menor proporção de folhas em suas camadas superiores, reduzindo o tamanho do bocado (Stobbs, 1973b), em razão da dificuldade de preensão da forragem com longas hastes (Barthram \& Grant, 1984). Stobbs (1973b) observou elevação da altura do dossel de Setaria anceps e Chloris gayana de 15 para $60 \mathrm{~cm}$ e redução na proporção de folhas de 83 para 44\%, com o aumento da duração do crescimento de duas para oito semanas. O mesmo padrão de resposta também foi verificado por Silva et al. (1994b), em pastagem de Pennisetum purpureum cv. Mott.

A densidade do dossel afeta o consumo, tanto pela distribuição horizontal de seus perfilhos e pela densidade populacional de perfilhos (DPP) quanto pela distribuição vertical de suas folhas - densidade de folhas. A menor DPP afeta negativamente a taxa de ingestão (Ungar \& Noy-Meir, 1988), por comprometer o tamanho do bocado, que não é compensado pelo aumento na taxa de bocado (Black \& Kenney, 1984), acarretando redução do consumo. Também afeta negativamente o tamanho do bocado, em decorrência do maior tamanho individual dos perfilhos, com maior proporção de tecidos de sustentação, que são evitados pelo animal no momento da preensão da forragem (Flores et al., 1993). Por sua vez, a menor densidade da folhas afeta negativamente o tamanho do bocado, em função da redução na profundidade do bocado ser proporcionalmente maior que o aumento na área do bocado (Laca et al., 1992). Da mesma forma, Stobbs 
(1973a) verificou menores bocados de forragem em piquetes com dosséis com menor densidade de forragem, em resposta à restrição do nível de nitrogênio no solo e à aplicação de estimulantes de crescimento.

A relação folha/colmo também tem influência sobre o consumo, em razão da preferência dos animais pelas folhas (Forbes \& Hodgson, 1985), que apresentam maior facilidade de preensão, além de maior valor nutritivo. Ainda que o animal possa compensar o menor valor nutritivo da forragem pastejando seletivamente (Chacon \& Stobbs, 1976), o consumo pode ser comprometido pela redução na taxa de bocado (Forbes \& Hodgson, 1985).

A duração do período de pastejo afeta o valor nutritivo do dossel, sua condição e o desempenho do animal. Parsons \& Penning (1988) verificaram redução na digestibilidade in vitro da matéria orgânica de Lolium perenne em extrusa de ovinos, ao longo de de 19 dias pastejo. Isso se explica pela redução na proporção de folhas e maior proporção de hastes e de material morto nas camadas inferiores do dossel, em decorrência da progressiva desfolhação no decorrer do período de pastejo, resultando em comprometimento no consumo (McGilloway et al., 1999). Assim, Blaser et al. (1959) relataram queda de 15,4 para 13,6 kg na produção diária de leite por vaca, ao longo de nove dias de pastejo.

Este estudo foi conduzido com o objetivo de se avaliar os efeitos da duração dos períodos de descanso e de pastejo sobre o valor nutritivo da forragem e o desempenho de novilhos pastejando Panicum maximum cv. Mombaça sob lotação intermitente, com os períodos de descanso definidos pelo número de novas folhas expandidas por perfilho.

\section{Material e Métodos}

O experimento foi conduzido na Central de Experimentação, Pesquisa e Extensão do Triângulo Mineiro (CEPET/UFV), localizada a 18 $41^{\prime}$ S, 49³4'O, no período de novembro de 2000 a março de 2001, para se estimar as variações da composição química e da digestibilidade de amostras de forragem colhidas manualmente (pastejo simulado), além do consumo de forragem e do ganho de peso de novilhos sob pastejo em piquetes do cultivar Mombaça de Panicum maximum, sob lotação intermitente, com três períodos de descanso.
Três tratamentos (períodos de descanso) foram definidos com base no tempo necessário para a expansão de 2,5; 3,5 e 4,5 novas folhas por perfilho, após período de pastejo de seis dias. Visto que a gramínea mantém, em média, 3,5 folhas verdes por perfilho (Gomide \& Gomide, 2000), assumiu-se que o mais longo período de descanso coincide com a senescência e morte da primeira folha expandida, resultando em ineficiência de utilização da forragem produzida.

A área experimental de 6 ha foi dividida em cinco piquetes sob a freqüência de desfolha de 2,5 novas folhas e seis piquetes por tratamento dos dois mais longos períodos de descanso. As áreas dos piquetes, que variaram inversamente com a duração dos seus períodos de descanso, eram de 2,350, 1.600 e $1.200 \mathrm{~m}^{2}$, destinados aos tratamentos 2,5; 3,5 e 4,5 folhas, respectivamente. O restante da área experimental foi utilizado como área de reserva.

Adubação em cobertura, com $250 \mathrm{~kg} / \mathrm{ha}$ da fórmula 20-5-20, foi aplicada em cada piquete, antes da roçada da vegetação, ocorrida no início da estação de crescimento (primeiro ciclo de pastejo); esta adubação foi repetida à saída dos novilhos de cada piquete, antes do terceiro ciclo de pastejo. Foram utilizados 15 novilhos mestiços (Holandês-Zebu), como animais de prova, além de outros, como animais de equilíbrio. A cada tratamento (período de descanso) correspondeu um grupo de cinco novilhos, que pastejou durante seis dias do ciclo de pastejo, em cada piquete do respectivo tratamento. Quando necessário, estes animais permaneceram na área de reserva, após pastejarem o último piquete do ciclo de pastejo de seu tratamento, à espera de que o piquete primeiramente pastejado apresentasse o número previsto de folhas por perfilho, iniciando-se novo ciclo de pastejo. Novilhos de equilíbrio, mantidos na área de reserva, eram introduzidos nos piquetes, quando necessário, para garantir-lhe IAF de 2,0, ao final de cada período de pastejo.

No início e final de cada ciclo de pastejo, foram efetuadas pesagens dos animais de prova, para se estimar o seu desempenho. Os novilhos de cada tratamento foram conduzidos ao curral ao final do último dia de pastejo de cada ciclo e pesados, após jejum de aproximadamente 15 horas (Coates \& Penning, 2000). Depois de pesados, foram conduzidos à área de reserva, se necessário, até que a vegetação do primeiro piquete de cada tratamento alcançasse sua condição de pastejo preconizada (2,5; 3,5 ou 4,5 novas folhas expandidas por perfilho), quando, então, 
foram novamente pesados, após jejum, e conduzidos a este piquete, para se iniciar novo ciclo de pastejo.

Após alguns ciclos de pastejo, quando o efeito dos períodos de descanso se manifestara sobre as características da forragem, foi avaliado o seu valor nutritivo, por intermédio das estimativas de:

a) Digestibilidade in vitro da matéria seca (DIVMS) da dieta, estimada conforme Tilley \& Terry (1963), em amostras da forragem colhidas manualmente, simulando o pastejo dos animais no primeiro, terceiro e quinto dias de pastejo nos piquetes em que o ensaio de consumo foi conduzido. Essa amostragem foi efetuada sempre à tarde, procurando-se colher, manualmente, forragem representativa daquela selecionada pelos animais, observando-lhes o comportamento, até que se obtivesse uma amostra de aproximadamente $400 \mathrm{~g}$, em cada piquete. Essas amostras foram levadas ao laboratório, acondicionadas em saco de papel e colocadas em estufa de ventilação forçada a $65^{\circ} \mathrm{C}$ por 72 horas. Em seguida, foram processadas em moinho estacionário “Thomas Wiley”, utilizando-se peneira com malha de $1 \mathrm{~mm}$, e guardadas em vidros com tampa, para posteriores análises laboratoriais.

Além da DIVMS, foram também determinados os teores de proteína bruta (PB), pelo método de Kjeldahl (AOAC, 1984), descrito por Silva (1990) e dos constituintes da fração fibrosa (teores de fibra em detergentes neutro [FDN] e ácido [FDA] e de lignina), segundo método proposto por Goering \& Van Soest (1970);

b) Consumo de forragem: calculado a partir das estimativas de excreção de matéria seca fecal e da DIVMS. A matéria seca fecal (MS fecal) foi estimada utilizando-se óxido crômico $\left(\mathrm{Cr}_{2} \mathrm{O}_{3}\right)$ como indicador externo, a partir da relação entre a quantidade de óxido crômico $\left(\mathrm{Cr}_{2} \mathrm{O}_{3}\right)$ ministrada ao animal e sua concentração nas fezes, estimada conforme Williams et al. (1962).

Para a estimativa da excreção fecal, foram utilizados quatro novilhos rúmen-fistulados, adultos com peso acima de $383 \mathrm{~kg}$, até então alheios ao experimento, que receberam $10 \mathrm{~g}$ de $\mathrm{Cr}_{2} \mathrm{O}_{3}$ diariamente, divididos em duas doses ( $5 \mathrm{~g}$ pela manhã e $5 \mathrm{~g}$ à tarde) via fístula ruminal durante 24 dias, com período de nove dias para adaptação dos novilhos ao manejo e para atingir o estado de equilíbrio do fluxo de $\mathrm{Cr}_{2} \mathrm{O}_{3}$ no trato gastrintestinal. Cada um dos quatro novilhos fistulados, constituindo um bloco, pastejou um piquete de cada tratamento durante cinco dias, de modo a pastejar, em 15 dias, três piquetes de cada um dos tratamentos 2,5; 3,5 e 4,5 folhas, cuja ordem foi casualizada. Durante cada período de cinco dias em cada piquete, as aplicações diárias de $\mathrm{Cr}_{2} \mathrm{O}_{3}$ foram continuadas, duas vezes ao dia, quando também foram realizadas as coletas de fezes, diretamente do reto, perfazendo em torno de $500 \mathrm{~g}$ de matéria fecal fresca por novilho. As amostras de fezes foram levadas à estufa e secas a $65^{\circ} \mathrm{C}$. O consumo de forragem foi calculado segundo a fórmula:

$$
\mathrm{C}=\frac{\text { MS fecal }}{1-\text { DIVMS }}
$$

em que: $\mathrm{C}=$ consumo de forragem (g MS/dia $\times$ novilho); MS fecal = matéria seca fecal $(\mathrm{g} / \mathrm{dia} \times$ novilho); DIVMS = digestibilidade in vitro da matéria seca da forragem.

Os dados de teores de PB, FDN, FDA, lignina e de DIVMS foram submetidos à análise de regressão pelo procedimento GLM do pacote estatístico SAS (SAS Institute, 1999), adotando-se os valores médios de 32, 44 e 54 dias, respectivamente, para os períodos de descanso de 2,5; 3,5 e 4,5 folhas por perfilho (Cândido et al., 2005), segundo o modelo:

$$
\mathrm{Y}_{\mathrm{ijk}}=\mu+\mathrm{T}_{\mathrm{i}}+\mathrm{D}_{\mathrm{j}}+(\mathrm{TD})_{\mathrm{ij}}+\mathrm{e}_{\mathrm{ijk}}
$$

em que: $\mathrm{Y}_{\mathrm{ijk}}=$ observação relativa ao $\mathrm{k}$ 무 piquete, no

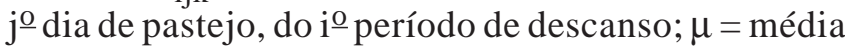
da população; $\mathrm{T}_{\mathrm{i}}=$ efeito do $\mathrm{i}^{\mathrm{O}}$ período de descanso; $\mathrm{i}=1,2,3 ; \mathrm{D}_{\mathrm{j}}=$ efeito do $\mathrm{j}$ - dia de pastejo; $\mathrm{j}=1,2,3$; $(\mathrm{TC})_{\mathrm{ij}}=$ interação do $\mathrm{i}^{\mathrm{O}}$ período de descanso com o j $\mathrm{o}$ dia de pastejo; $\mathrm{e}_{\mathrm{ijk}}=$ efeito aleatório relativo ao $\mathrm{k}^{\underline{0}}$ piquete, no $\mathrm{j}$ dia de pastejo, do i${ }^{\mathrm{O}}$ período de descanso; $\mathrm{k}=1,2,3$ piquetes (unidades experimentais).

Os dados de consumo de forragem foram analisados por regressão, adotando-se o procedimento GLM do pacote estatístico SAS (SAS, 1999), segundo o modelo:

$$
Y_{i j}=\mu+T_{i}+B_{j}+e_{i j}
$$

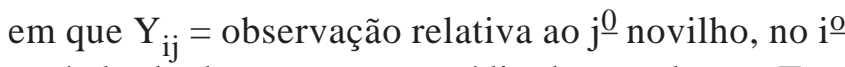
período de descanso; $\mu$ = média da população; $T_{i}=$ efeito do $\mathrm{i}^{\mathrm{O}}$ período de descanso; $\mathrm{i}=1$, 2, 3 ; $\mathrm{B}_{\mathrm{j}}=$ efeito do jônovilho (bloco); j = 1, 2, 3 e 4 ; e $\mathrm{e}_{\mathrm{ij}}=$ efeito aleatório relativo ao $\mathrm{j}^{\underline{0}}$ novilho, no $\mathrm{i}^{\underline{0}}$ período de descanso, considerando-se negligenciável a interação $\mathrm{TB}_{\mathrm{ij}}$. 


\section{Resultados e Discussão}

As estimativas médias das variáveis associadas ao valor nutritivo das amostras de forragem colhidas manualmente (pastejo simulado) encontram-se nas Tabelas 1 e 2. Observou-se elevados teores de FDN e FDA, característicos de forrageiras do grupo $\mathrm{C}_{4}$, sem diferença atribuível aos períodos de descanso, que elevaram linearmente $(\mathrm{P}<0,05)$ com os dias de pastejo (D), segundo as equações: $\hat{Y}=65,20+1,061^{*}$ $\mathrm{D} ; \mathrm{r}^{2}=0,63$ e $\hat{\mathrm{Y}}=30,61+1,124^{*} \mathrm{D} ; \mathrm{r}^{2}=0,62$, respectivamente. Os teores de FDN e FDA cresceram diariamente 1,061 e 1,124 pontos percentuais $(\mathrm{P}<0,05)$ durante o período de pastejo, respectivamente.

Os teores de lignina, relativamente baixos, elevaram $(\mathrm{P}<0,01)$ com a duração do período de descanso (P) e reduziram no decorrer os dias de pastejo (D), segundo a equação:

$$
\hat{\mathrm{Y}}=3,08+0,082^{* *} \mathrm{P}-0,348^{* *} \mathrm{D} ; \mathrm{r}^{2}=0,80
$$

A idade da planta é um dos fatores de declínio no valor nutritivo da forragem, principalmente nas gramíneas do grupo $\mathrm{C}_{4}$, cuja parede secundária experimenta espessamento (Wilson \& Kennedy, 1996) e lignificação durante o crescimento da forrageira (Titgemeyer et al., 1996); entretanto, no presente estudo, o valor nutritivo da forragem foi mais influenciado pelos dias de pastejo.

$\mathrm{O}$ teor de proteína bruta variou $(\mathrm{P}<0,01)$ em função da duração dos períodos de descanso e dos dias de pastejo, segundo a equação: $\hat{Y}=66,02$ $0,739^{* *} \mathrm{D}-3,152 \mathrm{P}+0,044^{* *} \mathrm{P}^{2} ; \mathrm{r}^{2}=0,87$. O ponto de mínimo correspondeu à idade de 44 dias, valor médio observado para o período de descanso relativo ao aparecimento de 3,5 novas folhas. Para este ponto de mínimo, as respostas críticas relativas ao $1^{\circ}, 3^{\circ} \mathrm{e}$ $5^{\circ}$ dias de pastejo foram de 9,3; 8,5 e 6,3\% PB, respectivamente.

Andrade \& Gomide (1971) relataram redução de quase $50 \%$ no teor de PB do capim-elefante Taiwan A-146 com o avançar da idade de 28 para 56 dias. A proximidade dos teores de PB das amostras de forragem relativas aos tratamentos de 4,5 e 2,5 folhas (Tabela 1) deve ser atribuída à técnica de amostragem de pastejo simulado.

A DIVMS decresceu linearmente $(\mathrm{P}<0,05)$ com o prolongamento dos períodos de descanso e de pastejo, segundo a equação: $\hat{Y}=77,65-0,265^{*} \mathrm{P}-$ $1,223^{*} \mathrm{D} ; \mathrm{r}^{2}=0,71$.

Tabela 1 - Teores de fibra em detergente neutro (FDN) e ácido (FDA), de lignina, de proteína bruta (PB) e digestibilidade in vitro da matéria seca (DIVMS) da forragem amostrada manualmente em piquetes sob três períodos de descanso

Table 1 - Neutral (NDF) and acid (ADF) detergent fiber, lignin and crude protein (CP) contents and "in vitro" dry matter digestibility (IVDMD) of hand plucked forage samples of paddocks under three rest periods

\begin{tabular}{lccccc}
\hline $\begin{array}{l}\text { Período de descanso } \\
\text { Rest period }\end{array}$ & $\begin{array}{c}\text { FDN } \\
\text { NDF }\end{array}$ & $\begin{array}{c}\text { FDA } \\
\text { ADF }\end{array}$ & $\begin{array}{c}\text { Lignina } \\
\text { Lignin }\end{array}$ & $\begin{array}{c}\text { PB } \\
C P\end{array}$ \\
\hline 2,5 folhas (2.5 leaves) & 67,8 & 32,4 & \% MS (\% DM) & 6,3 & 10,4 \\
3,5 folhas (3.5 leaves) & 69,4 & 35,1 & 4,9 & 7,9 & 63,4 \\
4,5 folhas (4.5 leaves) & 68,2 & 34,3 & 5,5 & 9,7 & 63,8 \\
\hline
\end{tabular}

Tabela 2 - Teores de fibra em detergente neutro (FDN) e ácido (FDA), de lignina, de proteína bruta (PB) e digestibilidade in vitro da matéria seca (DIVMS) da forragem amostrada manualmente, pastejo simulado, durante o período de pastejo

Table 2 - Neutral (NDF) and acid (ADF) detergent fiber, lignin and crude protein (CP) contents and "in vitro" dry matter digestibility (IVDMD) of hand plucked forage samples, during the grazing period

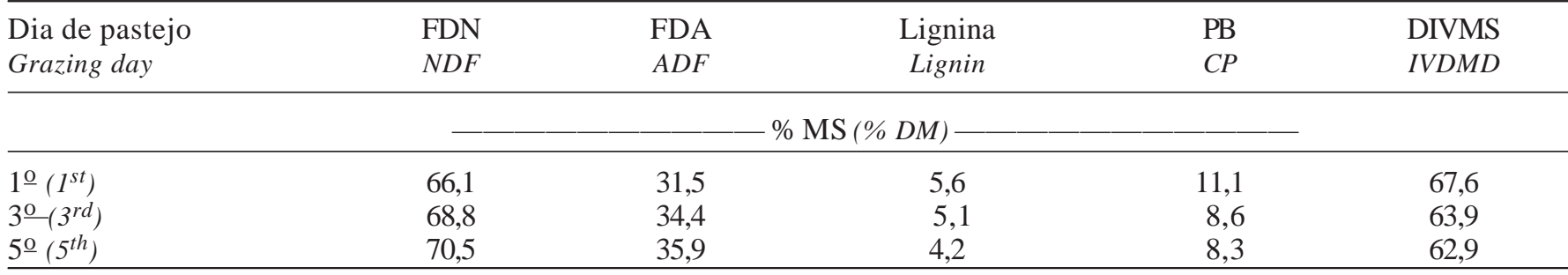


Assim, pode-se reconhecer ser pequena a superioridade das amostras dos piquetes sob menor período de descanso (Tabela 1), atribuível aos seus teores mais favoráveis de proteína bruta e lignina e à mais alta digestibilidade da matéria seca. Entretanto, a duração do período de pastejo revelou-se de maior importância sobre o valor nutritivo da forragem sob pastejo de lotação intermitente. A progressiva desfolha do dossel com o decorrer do período de pastejo, relatada por Chacon \& Stobbs (1976) e por McGilloway et al. (1999), resultou em comprometimento $(\mathrm{P}<0,05)$ do valor nutritivo da forragem, com redução de seu teor de PB, elevação de seus teores de FDN, FDA e lignina e conseqüente redução da DIVMS. A diminuição do valor nutritivo da forragem no decorrer de longo período de pastejo tem reflexos negativos sobre o desempenho animal, como queda na produção diária de leite por vaca (15,4 a 13,6 kg) ao longo de nove dias de pastejo (Blaser et al., 1959).

O consumo de forragem, com valores variando de 1,89 e 1,67\%, para animais em pastejo nos piquetes sob períodos de descanso de 2,5 e 4,5 folhas, respectivamente, não foi afetado $(\mathrm{P}>0,05)$ pelos períodos de descanso, observando-se consumo médio $\hat{Y}=\mathrm{Y}=1,81 \%$. Esse resultado é inesperado, não tanto pelo mais elevado teor de PB e pela mais alta DIVMS das amostras dos piquetes sob menor período de descanso (Tabela 1), mas sobretudo pela mais larga relação folha/colmo de sua forragem (Cândido et al., 2005), importante característica favorável ao consumo (Stobbs, 1973a; Moore \& Sollenberg, 1997).

As estimativas de consumo do presente estudo podem ser consideradas baixas, relativamente às estimativas do valor nutritivo das amostras de forragem. Entretanto, segundo Duble (1971), outros fatores, como a biomassa forrageira e suas características estruturais, determinam o consumo de forragem pelos ruminantes em pastejo. Sob condição não-limitante de quantidade de forragem, o consumo é função da qualidade da forrageira. Segundo esse autor, o desempenho animal, que se correlaciona estreita e positivamente com o consumo de forragem, só é comprometido ao serem consumidas forragens com digestibilidade da matéria seca acima de $60 \%$, quando a massa de forragem verde for inferior a $500 \mathrm{~kg} / \mathrm{ha}$. Entretanto, no presente estudo, a massa de forragem foi muito acima deste valor crítico.

Euclides et al. (2000) verificaram consumo de forragem superior a 2,5\% PV em piquetes de espécies do gênero Brachiaria, cujas extrusas apresentaram teores de PB em torno de 8,5\%. Para cultivares de Panicum maximum, no entanto, Euclides et al. (1999) observaram consumo médio acima de $2,3 \%$ PV por novilhos, cujas extrusas apresentavam teores médios de PB entre 9,4 e 12,0\%.

A baixa estimativa de consumo observada neste estudo pode ser atribuída à categoria dos animais fistulados (adultos, com peso acima de $383 \mathrm{~kg}$ ), enquanto, no estudo de Euclides et al. (2000), os novilhos apresentavam peso corporal de 220 a $350 \mathrm{~kg}$. Além disso, enfatiza-se o elevado teor de FDN da forragem (Tabelas 1 e 2) (acima de 66\%), que, segundo Van Soest (1965), compromete o consumo de forragem

Estimativas das taxas de lotação, do período experimental, ganho médio diário (GMD) e de outros fatores pertinentes à estimativa do rendimento de peso vivo (PV) por hectare, em resposta aos períodos de descanso, são apresentadas na Tabela 3. Estas estimativas não foram analisadas estatisticamente, em razão da ausência de repetição "verdadeira" (conjunto de piquetes sob cada um dos períodos de descanso estudados) (Fisher, 1999).

O GMD dos novilhos em pastejo nos piquetes sob período de descanso de 2,5 folhas foi $62,6 \%$ superior ao dos novilhos em pastejo nos piquetes sob maior período de descanso (Tabela 3). A partir da comparação dos dados de valor nutritivo das forragens (Tabela 1) com os GMDs dos novilhos, pode-se aventar duas hipóteses alternativas: a) as amostras de forragem não foram representativas das dietas dos novilhos; b) o desempenho animal foi comprometido nos piquetes sob período de descanso mais longo, pela redução de consumo de forragem, em razão das características estruturais menos favoráveis de seu dossel, sobretudo a estreita relação folha/colmo (Cândido et al., 2005).

O desempenho animal estimado pelos GMDs pode ser considerado razoável. Euclides et al. (1999) relataram GMD de 680 g/novilho x dia, durante a estação chuvosa, em animais pastejando três cultivares de Panicum maximum, cujos teores de PB e FDN se aproximaram daqueles observados neste ensaio. Sollemberger e Jones Jr. (1989) e Zeorvoudakis et al. (2001) relataram GMDS de 970 e $890 \mathrm{~g} /$ novilho x dia, em animais em pastejo em piquetes de Pennisetum purpureum e Brachiaria decumbens, respectivamente.

Enquanto no primeiro caso, o uso de doses mais elevadas de nitrogênio (160 kg/ha x ano) pode ter propiciado maior rendimento forrageiro e seletividade 
Período de Descanso, Valor Nutritivo e Desempenho Animal em Pastagem de Panicum maximum cv. Mombaça... 1465

Tabela 3 - Taxa de lotação por ciclo de pastejo (TL) e total (TLT), período experimental, taxa de lotação média (TLM) e ganho médio diário (GMD) dos novilhos, em resposta aos três períodos de descanso, no período das águas

Table 3 - Stocking rate per grazing cycle (SR), total stocking rate (TSR), experimental period, average stocking rate (ASR) and average steer daily gain (ADG), according to paddocks rest period during the rainy season

\begin{tabular}{|c|c|c|c|c|}
\hline & \multirow[t]{2}{*}{$\begin{array}{l}\text { Ciclo de pastejo } \\
\text { Grazing cycle }\end{array}$} & \multicolumn{3}{|c|}{$\begin{array}{c}\text { Período de descanso (novas folhas expandidas/perf) } \\
\text { Rest period (new expanded leaves/tiller) }\end{array}$} \\
\hline & & 2,5 & 3,5 & 4,5 \\
\hline $\begin{array}{l}\text { TL (dias-novilho/ha) } \\
\text { SR (steer-days/ha) }\end{array}$ & $\begin{array}{l}1^{\underline{0}}\left(1^{\text {st }}\right) \\
2^{\underline{o}}\left(2^{n d}\right) \\
3^{\underline{o}}\left(3^{r d}\right) \\
4^{\underline{0}}\left(4^{\text {th }}\right)\end{array}$ & $\begin{array}{l}246 \\
207 \\
164 \\
160\end{array}$ & $\begin{array}{c}321 \\
253 \\
225 \\
-\end{array}$ & $\begin{array}{c}388 \\
295 \\
- \\
- \\
\end{array}$ \\
\hline TLT (dias-novilho/ha) & & 776 & 799 & 684 \\
\hline $\begin{array}{l}\text { TSR (steer-days/ha) } \\
\text { Período experimental (dias) } \\
\text { Experimental period (days) }^{1}\end{array}$ & & 125 & 114 & 102 \\
\hline $\begin{array}{l}\text { TLM (novilhos/ha) } \\
\text { ASR (steers } / \text { ha) }\end{array}$ & & 6,2 & 7,0 & 6,7 \\
\hline $\begin{array}{l}\text { GMD (g/novilho } \times \text { dia }) \\
\text { ADG }(g / \text { steer } \times \text { day })\end{array}$ & & 704 & 546 & 433 \\
\hline
\end{tabular}

${ }^{1}$ Contado a partir do primeiro dia de pastejo no primeiro piquete no primeiro ciclo de pastejo até o último dia de pastejo do último piquete ocupado no último ciclo de pastejo.

${ }^{1}$ Counted from the first grazing day of the first grazing cycle up to the last grazing day of the last grazing cycle.

2 Novilhos com peso corporal médio de $335 \mathrm{~kg}$.

${ }^{2}$ Average steers body weight of $335 \mathrm{~kg}$.

pelo animal, no segundo, a baixa lotação utilizada (1,1 novilho/ha) também teria permitido maior seletividade pelos animais em pastejo em relação ao presente estudo. Além disso, as elevadas temperaturas máximas diárias observadas durante o período experimental (Cândido et al., 2005) podem ter contribuído para o menor desempenho dos animais, que relutavam em pastejar nas horas mais quentes do dia, reduzindo assim o tempo de pastejo.

Observou-se (Tabela 3) tendência de menor TL por ciclo de pastejo, dos piquetes sob período de descanso mais curto, como conseqüência de sua menor massa de forragem (Cândido et al., 2005). TLs similares dos piquetes sob período de descanso de 3,5 ou 4,5 folhas decorreriam do critério para o encerramento do período de pastejo. Em razão de a cultivar Mombaça manter 3,5 folhas verdes por perfilho (Gomide \& Gomide, 2000), e em decorrência do intenso alongamento de colmo nos piquetes sob 0 mais longo período de descanso, grande parte da massa seca de forragem nestes piquetes era colmo (Cândido et al., 2005), fração rejeitada pelos animais. Embora o mais longo período de descanso tenha propiciado $1.190 \mathrm{~kg} / \mathrm{ha}$ de massa seca de forragem a mais, em relação ao período de descanso intermediário, a vanta- gem do mesmo em termos de massa seca de lâminas foliares verdes reduziu-se a $442 \mathrm{~kg} / \mathrm{ha}$ (Cândido et al., 2005). Portanto, o mais longo período de descanso não foi vantajoso em termos de taxa de lotação, relativamente ao de 3,5 novas folhas por perfilho.

Verificou-se, ainda, redução na taxa de lotação com o avançar dos ciclos de pastejo sob qualquer dos tratamentos, em decorrência do comprometimento da taxa de crescimento da vegetação à medida que se aproximava o final da estação chuvosa.

Apesar da menor taxa de lotação observada em qualquer dos ciclos de pastejo com período de descanso de 2,5 folhas, comparativamente ao período de descanso intermediário e desse com o período de descanso mais longo, houve aumento no número de ciclos de pastejo, propiciado pelo menor tempo de descanso. A conseqüência disso é a proximidade dos valores de lotação total (dias-novilho/ha) para os tratamentos de períodos de descanso curto e intermediário, ambos com valores mais altos relativamente ao mais longo período de descanso. Ou seja, quando se considera toda a estação de pastejo, a desvantagem do período de descanso de 2,5 folhas, em termos de taxa de lotação por ciclo de pastejo, é compensada pelo seu maior número de ciclos de pastejo. 


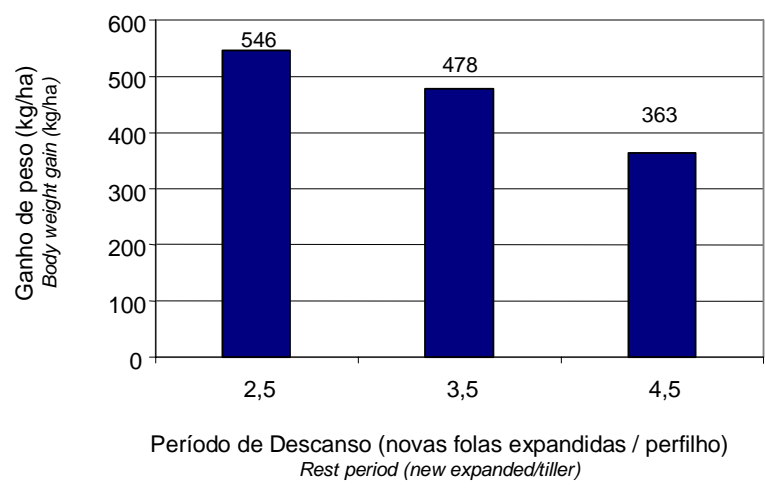

Figura 1 - Rendimento de peso vivo ao longo de 125 dias, na estação chuvosa (novembro a março), em piquetes de Panicum maximum cv. Mombaça sob três períodos de descanso.

Figure 1 - Body weight gain over 125 days in the rainy season (November to March) in Panicum maximum cv. Mombaça paddocks under three rest periods.

O rendimento de peso vivo por unidade de área ( $\mathrm{kg} / \mathrm{ha})$, para os três períodos de descanso, ao longo de 125 dias de pastejo nas águas é apresentado na Figura 1, que indica maior rendimento de PV sob período de descanso de 2,5 folhas, em razão do melhor desempenho animal nos respectivos piquetes. Por outro lado, rendimento de PV mais baixo nos piquetes sob mais longo período de descanso decorre principalmente do menor GMD estimado para os respectivos novilhos.

\section{Conclusões}

Os períodos de descanso estudados não resultaram em substanciais diferenças no valor nutritivo da forragem, que foi mais afetado pela duração do período de pastejo. Entretanto, os períodos de descanso resultaram em grandes diferenças no desempenho e no rendimento animal. O mais longo período de descanso comprometeu o desempenho animal e, conseqüentemente, o rendimento animal, ao longo da estação de pastejo.

O período de descanso de piquetes do cultivar Mombaça de Panicum maximum não deve exceder o tempo necessário para a expansão de 2,5 novas folhas por perfilho.

\section{Literatura Citada}

ALLDEN, W.G.; WHITTAKER, I.A.McD. The determinants of herbage intake by grazing sheep: the interrelationship of factors influencing herbage intake and availability.
Australian Journal of Agricultural Research, v.21, n.5, p.755-766, 1970.

ANDRADE, I.F.; GOMIDE, J.A. Curva de crescimento e valor nutritivo do capim-elefante (Pennisetum purpureum Schum.) ‘A-146 Taiwan’. Ceres, v.18, p.431-447, 1971.

BARTHRAM, G.T.; GRANT, S.A. Defoliation of ryegrassdominated swards by sheep. Grass and Forage Science, v.39, n.3, p.211-219, 1984.

BLACK, J.L.; KENNEY, P.A. Factors affecting diet selection by sheep. II - Height and density of pasture. Australian Journal of Agricultural Research, v.35, n.5, p.565-578, 1984.

BLASER, R.E.; BRYANT, H.T.; WARD, C.Y. et al. Animal performance and yields with methods of utilizing pasturage. Agronomy Journal, v.51, n.4, p.238-242, 1959.

BRYAN, W.B.; PRIGGE, E.C.; LASAT, M. et al. Productivity of Kentucky Bluegrass pasture grazed at three heights and two intensities. Agronomy Journal, v.92, n.1, p.30-35, 2000.

CÂNDIDO, M.J.D.; GOMIDE, C.A.M.; ALEXANDRINO, E. et al. Morfofisiologia do dossel de Panicum maximum cv. Mombaça sob lotação intermitente com três períodos de descanso. Revista Brasileira de Zootecnia, v.34, n.2, p.406-415, 2005.

CHACON, E.; STOBBS, T.H. Influence of progressive defoliation of a grass sward on the eating behaviour of cattle. Australian Journal of Agricultural Research, v.27, n.5, p.709-727, 1976.

COATES, D.B.; PENNING, P. Measuring animal performance. In: MANNETJE, L.; JONES, R.M. (Eds.). Field and laboratory methods for grassland and animal production research. Wallingford: CAB International, 2000. p.353-402

COSGROVE, G.P. Grazing behaviour and forage intake. In: SIMPÓSIO INTERNACIONAL SOBRE PRODUÇÃO ANIMAL EM PASTEJO, 1997, Viçosa, MG. Anais... Viçosa, MG: Universidade Federal de Viçosa, 1997. p.59-80.

DUBLE, R.L.; LANCASTER, J.A.; HOLT, E.C. Forage characteristics limiting animal performance of warmseason perennial grasses. Agronomy Journal, v.63, n.5, p.795-798, 1971.

EUCLIDES, V.P.B.; THIAGO, L.R.L.S.; MACEDO, M.C.M. et al. Consumo voluntário de forragem de três cultivares de Panicum maximum sob pastejo. Revista Brasileira de Zootecnia, v.28, n.6, p.1177-1185, 1999.

EUCLIDES, V.P.B.; CARDOSO, E.G.; MACEDO, M.C.M. et al. Consumo voluntário de Brachiaria decumbens cv. Basilisk e Brachiaria brizantha cv. Marandu sob pastejo. Revista Brasileira de Zootecnia, v.29, n.6, p.2200-2208, 2000 (supl.2).

FISHER, D.S. Defining the experimental unit in grazing trials. In: AMERICAN SOCIETY OF ANIMAL SCIENCE, 1999, United States. Proceedings... United States: ASAS, 1999. p.1-5.

FLORES, E.R.; LACA, E.A.; GRIGGS, T.C. et al. Sward height and vertical morphological differentiation determine cattle bite dimensions. Agronomy Journal, v.85, n.3, p.527-532, 1993.

FORBES, T.D.A.; HODGSON, J. Comparative studies of the influence of sward conditions on the ingestive behaviour of cows and sheep. Grass and Forage Science, v.40, n.1, p.69-77, 1985.

GOERING, H.K.; Van SOEST, P.J. Forage fiber analyses (Apparatus, reagents, procedures and some applications). Washington: USDA-ARS, 1970. 20p. (USDA-ARS. Agriculture Handbook, 379) 
GOMIDE, C.A.M.; GOMIDE, J.A. Morfogênese de cultivares de Panicum maximum Jacq. Revista Brasileira de Zootecnia, v.29, n.2, p.341-348, 2000.

GOMIDE, C.A.M.; GOMIDE, J.A.M. The duration of regrowth period and the structural traits in a rotationally grazed Panicum maximum sward. In: INTERNATIONAL GRASSLAND CONGRESS, 19., 2001, São Pedro. Proceedings... Piracicaba: Fundação de Estudos Agrários Luiz de Queiroz, 2001. (CD-ROM)

LACA, E.A.; UNGAR, E.D.; SELIGMAN, N., et al. Effects of sward height and bulk density on bite dimensions of cattle grazing homogeneous swards. Grass and Forage Science, v.47, n.1, p.91-102, 1992.

McGILLOWAY, D.A.; CHUSHNAHAN, A.; LAIDLAW, A.S. et al. The relationship between level of sward height reduction in a rotationally grazed sward and short-term intake rates of dairy cows. Grass and Forage Science, v.54, n.2, p.116-126, 1999.

MOORE, J.E.; SOLLENBERGER, E. Techniques to predict pasture intake. In: SIMPÓSIO INTERNACIONAL SOBRE PRODUÇÃO ANIMAL EM PASTEJO, 1997, Viçosa, MG. Anais... Viçosa, MG: Universidade Federal de Viçosa, 1997. p.59-80.

MOTAZEDIAN, I.; SHARROW, S.H. Defoliation frequency and intensity effects on pasture forage quality. Journal of Range Management, v.43, n.2, p.198-200, 1990.

PARSONS, A.J.; PENNING, P.D. The effect of the duration of regrowth on photosynthesis, leaf death and the average rate of growth in a rotationally grazed sward. Grass and Forage Science, v.43, p.15-27, 1988.

REID, J.T.; KENNEDY, W.K.; TURK, K.L. et al. What is forage quality from the animal standpoint. Agronomy Journal, v.51, p.213-216, 1959.

SANTOS, P.M.; CORSI, M.; BALSALOBRE, M.A.A. Efeito da freqüência de pastejo e da época do ano sobre a produção e a qualidade em Panicum maximum cvs. Tanzânia e Mombaça. Revista Brasileira de Zootecnia, v.28, n.2, p.244-249, 1999.

STATISTICAL ANALYSES SYSTEM - SAS. User's guide. Version 8.0. Cary: 1999. 2 CD-ROM.

SILVA, D.J. Análise de alimentos (métodos químicos e biológicos). 2.ed. Viçosa, MG: Universidade Federal de Viçosa, 1990. 165p.

SILVA, D.S.; GOMIDE, J.A.; FONTES, C.A.A. et al. Pressão de pastejo em pastagem de capim-elefante anão (Pennisetum purpureum, Schum. cv. Mott): 1 - Efeito sobre a estrutura e disponibilidade de pasto. Revista da Sociedade Brasileira de Zootecnia, v.23, n.2, p.249-257, 1994a.

SILVA, D.S.; GOMIDE, J.A.; QUEIROZ, A.C. Pressão de pastejo em pastagem de capim-elefante anão (Pennisetum purpureum, Schum. cv. Mott): Efeito sobre o valor nutritivo, consumo de pasto e produção de leite. Revista da Sociedade Brasileira de Zootecnia, v.23, n.3, p.453-464, 1994b.
SOLLENBERGER, L.E.; JONES JR., C.S. Beef production from nitrogen fertilized Mott dwarf elephantgrass and Pensacola Bahiagrass pastures. Tropical Grasslands, v.23, n.3, p.129-134, 1989.

STOBBS, T.H. The effect of plant structure on the intake of tropical pastures. I. Variation in the bite size of grazing cattle. Australian Journal of Agricultural Research, v.24, n.6, p.809-819, 1973a.

STOBBS, T.H. The effect of plant structure on the intake of tropical pastures. II. Differences in sward structure, nutritive value, and bite size of animals grazing Setaria anceps and Chloris gayana at various stages of growth. Australian Journal of Agricultural Research, v.24, n.6, p.821-829, 1973b.

TILLEY, J.M.A.; TERRY, R.A. A two-stage technique for the in vitro digestion of forage crops. The Journal of the British Grassland Society, v.18, n.2, p.104-111, 1963.

TITGEMEYER, E.C.; COCHRAN, R.C.; TOWNE, E.G. et al. Elucidation of factors associated with the maturity-related decline in degradability of big bluestem cell wall. Journal of Animal Science, v.74, n.3, p.648-657, 1996.

UNGAR, E.D.; NOY-MEIR, I. Herbage intake in relation to availability and sward structure: grazing processes and optimal foraging. Journal of Applied Ecology, v.25, n.3, p.1045-1062, 1988.

Van SOEST, P.J. Voluntary intake in relation to chemical composition and digestibility. Journal of Animal Science, v.24, n.3, p.834-843, 1965.

WILLIAMS, C.H.; DAVID, D.J.; IISMAA, O. The determination of chromic oxide in faeces samples by atomic absorption spectrophotometry. Journal of Agricultural Science, v.59, n.3, p.381-385, 1962.

WILSON, J.R.; KENNEDY, P.M. Plant and animal constraints to voluntary feed intake associated with fibre characteristics and particle breakdown and passage in ruminants. Australian Journal of Agricultural Research, v.17, n.2, p.199-225, 1996.

ZERVOUDAKIS, J.T.; PAULINO, M.F.; DETMANN, E. et al. Desempenho e características de carcaça de novilhos suplementados no período das águas. Revista Brasileira de Zootecnia, v.30, n.4, p.1381-1389, 2001. 